\title{
Interaction patterns within a multi-herbivore assemblage derived from stable isotopes
}

\author{
M. Miranda ${ }^{a}$, F. Dalerum ${ }^{\text {b,c }}$ and F. Parrini ${ }^{a}$
}

${ }^{a}$ Centre for African Ecology, School of Animal, Plant and Environmental Sciences, University of the Witwatersrand, Private Bag 3, Wits 2050, Johannesburg, South Africa

${ }^{\mathrm{b}}$ Centre for Wildlife Management, University of Pretoria, Pretoria, South Africa

c Mammal Research Institute, Department of Zoology and Entomology, University of Pretoria, Pretoria, South Africa

*Corresponding author: María Miranda

e-mail:maria.miranda@wits.ac.za;maria.mirandaroves@gmail.com

phone: +27 724962707 / +46761650244 fax (School): +27 117176494

\begin{abstract}
The ecological effects of consumer guilds are strongly driven by the relative resource use of included species. Here we use stable isotopes in faecal samples from 6 cooccurring mammalian herbivores in an African savanna to identify species-specific trophic niches and detect patterns of interactions between herbivores and their feeding resources. Species-specific foraging strategies were reflected in the faecal $\delta^{13} \mathrm{C}$ values, with species aligning along both a browser-grazer gradient and a niche breadth gradient. Within the broad foraging strategies outlined by $\delta^{13} \mathrm{C}, \delta^{15} \mathrm{~N}$ indicated a seasonal shift in resource use for some herbivores. We expected that ${ }^{13} \mathrm{C}$ isotope niches would overlap in a nested fashion, with the niches of grazers and browsers being included in those of mixed feeders, and that ${ }^{15} \mathrm{~N}$ niches would separate into discrete modules reflecting leguminous and protein content of respective diets. However, the observed structure was more complex, with combined modular and nested patterns of interactions between herbivores and ${ }^{13} \mathrm{C}$ isotopes. We identified an isolated module comprising eland and its exclusive $\delta^{13} \mathrm{C}$ values, and a series of nested structures with a set of specialist herbivores (hartebeest and sable) which $\delta^{13} \mathrm{C}$ values were nested within those of more generalist herbivores (impala, waterbuck and zebra). Networks based on $\delta^{15} \mathrm{~N}$, however, reflected a higher level of overlap in resource use with random patterns in herbivore interactions with resources, and only a significant modular interaction pattern during the dry season. We suggest that the combined modular and nested pattern of $\delta^{13} \mathrm{C}$ interactions reflect the simultaneous mutualistic and antagonistic characteristics of plant-herbivore interactions. We argue that such interaction patterns could stabilize ecosystems by constraining effects of perturbations to specific modules and by increasing functional redundancy through nested interactions.
\end{abstract}

Key words: herbivory, modularity, nestedness, network, savanna, trophic

\section{Ecological Complexity, In Press}




\section{Introduction}

Consumer-resource interactions pervade ecosystems, where the links between organisms through trophic exchanges form the core of modern ecosystem definitions (Smith and Smith, 2012). The overall effects of a consumer guild (i.e. groups of consumers with similar resource requirements) are determined by the resource use of each species as well as the overlap between them (Dalerum et al. ,2012a). Increasing overlap in resource use is expected among consumers with increasing physiological, ecological or genetic similarity and in turn, ecologically or genetically similar resources are expected to be utilized by the same range of consumers (Gómez et al., 2010). Such ecological redundancy has been linked to the stability and resilience of ecosystems (Dalerum et al., 2012a; Holling, 1973). Therefore, quantifying the nature and structure of resource use within consumer guilds is important for understanding the functioning of ecological systems and for adopting efficient conservation strategies in the face of human driven environmental change ( LaLiberté and Tylianakis, 2010; Memmott et al., 2007).

Large terrestrial herbivores are critically important for ecosystem dynamics and often regulate both lower and higher trophic levels (Hunter and Price, 1992). From a consumer perspective, three major functional groups of large mammalian herbivores have traditionally been distinguished: browsers, grazers and mixed feeders (Hofmann and Stewart, 1972). This is an evolutionary response to morphological and chemical differences of plant resources, with herbivores evolving different physiological adaptations in order to maximize energy and nutrient extraction from the diverse plant material available (lason and van Wieren, 1999; Robbins, 1993). In African savannas, the highly diverse plant communities combined with the high spatial heterogeneity and temporal variability of resources has lead to the evolution of equally diverse large herbivores assemblages that consist of species with different morphology, physiology, behaviour and life history traits (Fritz and Loison, 2006). This high diversity of both consumers and resources makes African herbivore assemblages an ideal model in which to address consumer-resource interaction patterns (Dobson, 2009).

Analysis of naturally occurring stable isotopes has become well established as a tool for investigating the resource use of consumers (Dalerum and Angerbjörn, 2005; Martínez del Río et al., 2009). For large African herbivores, stable isotopes of carbon and nitrogen in faeces, bone collagen, tooth enamel and hair have been utilized as useful proxies to quantify resource use (Cerling et al., 2003; Codron et al., 2007a; Sponheimer et al., 2003a). Different photosynthetic pathways cause plants to differ in their ${ }^{13} \mathrm{C}$ content so that grasses, which in African savannas follow the C4 pathway, are enriched in ${ }^{13} \mathrm{C}$ compared to forbs and woody plants that follow the C3 pathway (Farquhar et al., 1989). Determining ${ }^{13} \mathrm{C} /{ }^{12} \mathrm{C}$ isotope ratios in herbivores thus allow for discrimination between consumption of plants with different photosynthetic pathways, and subsequently to place herbivore foraging strategies along a grazing-browsing gradient. In contrast, plants differ in ${ }^{15} \mathrm{~N} /{ }^{14} \mathrm{~N}$ ratios primarily as a response to environmental conditions such as aridity, soil type, climate, source of $\mathrm{N}$ but also to plant and herbivore physiological mechanisms (Ambrose, 1991; Ambrose and De Niro, 1986; Codron et al., 2005a; Evans, 2001; Handley and Raven, 1992; Heaton, 1987; Sealy et al., 1987). Therefore, a combined evaluation of $\mathrm{C}$ and $\mathrm{N}$ may provide useful insights of the 
foraging ecology of herbivores beyond information strictly contained in the amount of $\mathrm{C} 3$ versus $\mathrm{C} 4$ plants in the diet.

In parallel with the re-emerging interest in community ecology, network analyses have been increasingly used to describe and quantify species trophic relationships (Ings et al., 2009; Miranda et al., 2013). A trophic network consists of at least two distinct sets of nodes (typically species) that are connected through resource utilization links (Elton, 1927; Harary, 1961). Quantifying the topology of such networks allows for formal evaluation of patterns of resource partitioning or overlap (Sugihara, 1984).

Evolutionary processes acting at the multi-specific and multi-trophic levels seem to constrain such ecological networks towards specific structures that confer ecological stability (Allesina and Pascual, 2008). Nestedness and modularity are two such topological patterns that have emerged as particularly important for ecosystem stability (Bascompte et al., 2003; Bastolla et al., 2009; Stouffer and Bascompte, 2011; Thébault and Fontaine, 2010). Nestedness describes an interaction structure where the resources used by specialist consumers are a subset of the resources used by more generalist consumers (Bascompte et al., 2003). Modularity describes an interaction structure where there are delimited sub-communities of consumers and resources, with more frequent and stronger interactions within each sub-community than between them (May, 1973; Prado and Lewinsohn, 2004).

African savannas are expected to experience important climatic changes that combined with widespread management interventions could lead to major changes in herbaceous structure, basal cover and plant community composition (Buitenwerf et al., 2011; IPPC, 2013; Kirtman et al., 2013; Rutherford et al., 1999). Since African savannas are largely driven by plant-herbivore interactions, it is imperative that we understand the structure of trophic interactions between herbivores and their resources to fully understand the consequences of the expected environmental changes. In this study we use $\mathrm{C}$ and $\mathrm{N}$ stable isotopes from herbivore faeces to (I) quantify the relative feeding ecology within an African large herbivore assemblage, and (II) to quantify the structure of the relationship between herbivores and their feeding resources using network analyses. African herbivores follow a grazer-browser gradient where some species adopt intermediate mixed feeding strategies. This is expected to be reflected in corresponding $\delta^{13} \mathrm{C}$ values. The ${ }^{13} \mathrm{C}$ isotope niches of mixed feeders are thus expected to include the niches of more specialist grazers in a nested hierarchical structure. We expect this nested structure to be stronger in the wet season compared to the dry season, because of the limited resource supply and quality during the latter. We subsequently also expect a reduced modularity in ${ }^{13} \mathrm{C}$ niches in the dry season. $\delta^{15} \mathrm{~N}$ values relate to the physiology of plants and herbivores. We expect lower $\delta^{15} \mathrm{~N}$ values in mixed feeders because of inclusion of ${ }^{15} \mathrm{~N}$-depleted, $\mathrm{N}_{2}$-fixating legumes in their diets (Delwiche et al., 1979; Ambrose and De Niro, 1986). In addition, grazers recycle more ${ }^{15} \mathrm{~N}$-depleted urea due to their lower consumption of crude protein, which should further lead to higher $\delta{ }^{15} \mathrm{~N}$ values in their faeces (Sealy et al., 1987). We predict a modular pattern in herbivore $\delta^{15} \mathrm{~N}$ networks, shaped by differences in dietary content in both leguminous plants and proteins between grazers and mixed feeders.

\section{Methods}




\subsection{Study system and study species}

The study was conducted in Kgaswane Mountain Reserve (KMR, $25^{\circ} 43^{\prime} \mathrm{S}, 27^{\circ} 11^{\prime} \mathrm{E}$ ), a 5300 ha protected area in the Magaliesberg Mountain Range, North West Province, South Africa. The area is fenced and elevation ranges from 1230 to $1660 \mathrm{~m}$. The topography is characterised by steep cliffs on the western and southern boundaries with a wide summit plateau of quartzite in the northern part of the reserve. Mean annual rainfall is $604 \mathrm{~mm}$ (coefficient of variation: 0.42 between 1980 and 2011, KMR weather station, $1119 \mathrm{~m}$ altitude), most of which falls during October-April, defining distinct wet and dry seasons. Annual average temperatures range from 11 to $27^{\circ} \mathrm{C}$ being highest from December to February and lowest between June and August (KMR weather station).

The study area lies in the transition zone between the mixed bushveld and the rocky highveld grassland vegetation types (Low and Rebelo, 1996), and contains plant and animal species associated with both. The grassland is dominated by the grasses Themeda triandra, Hyparrhenia hirta, Trachypogon spicatus and Elionurus muticus (Nel, 2000). The woodland is dominated by Protea caffra and Acacia caffra (Nel, 2000). The reserve hosts a population of over 500 large herbivores including: red hartebeest Alcelaphus buselaphus (98, estimated numbers), zebra Equus quagga (90), eland Taurotragus oryx (85), impala Aepyceros melampus (81), waterbuck Kobus ellipsiprymnus (68), sable antelope Hippotragus niger (45), mountain reedbuck Redunca fulvorufula (41), kudu Tragelaphus strepsiceros (15), blesbok Damaliscus pygargus (10), springbok Antidorcas marsupialis (7), klipspringer Oreotragus oreotragus (6), oribi Ourebia ourebi (6), roan antelope Hippotragus equinus (3), and common reedbuck Redunca arundinum (5) (Nel et al., 2011). Carnivores occur in low numbers in the area and include caracal Caracal caracal, aardwolf Proteles cristata, black-backed jackal Canis mesomelas, and leopard Panthera pardus.

Our focal species were the six most abundant large herbivores in the reserve: red hartebeest, zebra, eland, impala, waterbuck, and sable antelope. Eland has been described either as a browser (Watson and Owen-Smith, 2000) or mixed feeder favouring browsing (Gagnon and Chew, 2000), depending on local environmental conditions and resource availability in the study region (Sponheimer et al., 2003b). Impala is regarded as a mixed feeder that switches forage use according to seasonal changes in resource availability (Meissner et al., 1996; Skinner and Smithers, 1990; Van der Merwe and Marshal, 2012), while red hartebeest, sable antelope and waterbuck are primarily grazers (Cerling et al., 2003; Codron et al., 2007a; Gagnon and Chew, 2000; Hofmann and Stewart, 1972; Owen-Smith, 1997; Skinner and Smithers, 1990; Sponheimer et al., 2003b). Zebra is a non-ruminant that mainly feeds as a grazer (Schulz and Kaiser, 2013).

\subsection{Sample collection}

Fresh faecal samples of the six study species were collected opportunistically across the whole reserve during January and February 2012 (wet season) and August and September 2012 (dry season) whenever groups or single animals were located. Only one sample per group and day was collected to minimize interdependency between samples. Ten samples were obtained for each species and season except for red 
hartebeest during the dry season (8 samples) and eland, sable and zebra during the wet season ( 9 samples each). A total of 115 faecal samples were collected, air dried and stored at room temperature for analyses of $\mathrm{C}$ and $\mathrm{N}$ isotope ratios.

\subsection{Stable isotope analysis}

Faecal stable isotopes were analyzed at the isotopes laboratory at the Council for Scientific and Industrial Research (CSIR, Pretoria, South Africa). Samples were homogenized with a mortar and cleaned from surface attached lipids and contaminants by sonication for $15-20$ s and overnight immersion in $1 \% \mathrm{HCl}$. Cleaned samples were oven dried at $70^{\circ} \mathrm{C}$ for 48 hours and mill-ground into a homogenous powder. Sub samples weighing 0.6-0.7 mg were taken of the dried material and each packed in a tin capsule. ${ }^{13} \mathrm{C} /{ }^{12} \mathrm{C}$ and ${ }^{15} \mathrm{~N} /{ }^{14} \mathrm{~N}$ ratios were determined by on-line combustion in a Thermo Flash Elemental Analyser (1112 series) integrated via a Thermo Finnigan continuous flow III system with a Thermo Delta V Plus Isotope Ratio Mass Spectrometer. $\mathrm{C}$ isotope ratios were calculated as $\delta^{13} \mathrm{C}$ and those for $\mathrm{N}$ as $\delta^{15} \mathrm{~N}$ where $\delta$ represents the proportional deviation in parts per thousand (\%o) from a standard; $\delta=$ $1000\left(\left(R_{\text {sample }} / R_{\text {standard }}\right)-1\right)$, where $R$ is the ratio of heavy to light isotopes. Reference standards were Vienna PeeDee Belemnite for carbon and atmospheric $\mathrm{N}_{2}$ for nitrogen. Replicates of a gelatine standard (Merk Gel) within each analysis session allowed for mass and drift corrections. Standard deviation for repeated measurements was less than $0.1 \%$ for both ${ }^{13} \mathrm{C}$ and ${ }^{15} \mathrm{~N}$.

\subsection{Isotope niche determination}

We estimated isotope niche breadths for each species and season as the mean distance to group centroids (Layman et al., 2007). We determined the average Euclidean distance between the $\delta^{13} \mathrm{C}$ and $\delta^{15} \mathrm{~N}$ in each faecal sample and the centroid in twodimensional $\delta^{13} \mathrm{C}$ and $\delta^{15} \mathrm{~N}$ space for all samples of the focal species in that season (Dalerum et al., 2012b).

To test for main and interaction effects of species and season on isotope values as well as on isotope niche breadth we used linear models with $\delta^{13} \mathrm{C}, \delta^{15} \mathrm{~N}$, and Euclidean distance to centroids as response variables, and species, season and their two-way interaction as categorical predictors. In the models on $\delta^{13} \mathrm{C}$ and isotope niche breadth, we used an inverse variance power weight function to account for heteroscedasticity (Pinheiro and Bates, 2000). We used pairwise t-tests to evaluate seasonal differences within species in $\delta^{13} \mathrm{C}, \delta^{15} \mathrm{~N}$, and isotope niche breadth, and corrected the probabilities according to the false discovery rate method (Benjamini and Hochberg, 1995).

\subsection{Degree and structure of niche overlap}

To quantify the structure of the relationships between the different herbivore species and their isotope niches, we created interaction matrices with herbivores as rows and resource categories as columns with the strength between each herbivore and resource category determined by the number of faecal samples that had a value within a given resource category. These interaction matrices were used to build weighted interaction networks. Because the resources reflect two continuous variables, $\delta^{13} \mathrm{C}$ and

$\delta^{15} \mathrm{~N}$, we grouped these continuous variables into discrete equal interval categories, where the width of the interval was defined as the average standard deviation of $\delta^{13} \mathrm{C}$ 
or $\delta^{15} \mathrm{~N}$ values across all species. We created separated interaction networks for each element and season.

We calculated Horn-Morisita indices ( $\mathrm{C}_{\mathrm{H}}$, Appendix S1, Supplementary material) for each season to determine the level of niche overlap between herbivores within seasons (Horn 1966; Krebs 1989). We averaged indexes across all pairs to obtain a network level index. The index ranges from 0 (no overlap) to 1 (complete overlap). To evaluate if the observed values of niche overlap differed from those expected by chance we compared them against a reference distribution calculated from 1000 random matrices where the number of interactions and links from the original interaction matrix were retained.

To further describe patterns of degree overlap between species, we sequentially calculated modularity and nestedness indices for the weighted consumer-resource interaction networks (Lewinsohn and Prado, 2006). The network degree of modularity was derived using the QuaBiMo algorithm (Q, Barber, 2007, Appendix S2, Supplementary material), based on a hierarchical random graphs approach adapted for weighted bipartite networks (Clauset et al., 2008; Dormann and Strauss, 2013). Q ranges from 0 , indicating that links within modules are not higher than expected by chance, to a maximum value of 1 when modules are discretely delimited. To evaluate if $Q$ calculated for our networks deviated from random expectations we compared them against a reference distribution derived from 1000 random matrices where the marginal totals from the original interaction matrices were retained (Dormann et al., 2009).

We used the weighted-interaction nestedness index (WIN, Appendix S3, Supplementary material) to quantify network nestedness (Galeano et al., 2008) between the herbivores and resources. We only tested for nested patterns of interaction within non-isolated modules of our networks. To evaluate if the observed nestedness deviated from random expectations, we constructed 1000 random matrices, and compared our observed values against these distributions. The random matrices were constrained to contain observed values and retain the distribution of number of events in the links of the original interaction matrix but not to retain marginal totals. For ease of interpretation, we have presented nestedness values as the weighted nestedness estimator (WINE) that ranges from 0 (random structure) to 1 (total nestedness) (see calculation of WINE in Appendix S3, Supplementary material).

We compared the degree of overlap, modularity and nestedness across seasons for both the $\delta{ }^{13} \mathrm{C}$ and $\delta{ }^{15} \mathrm{~N}$ based networks, but only when the calculated indices differed significantly from random expectations. We calculated $1000 D$-values for each index (Horn-Morishita, modularity, nestedness) from each network (Manly, 1997), by subtracting the value of the index in the observed interaction matrix from the index values obtained for the 1000 generated random matrices (Gibson et al., 2011; Vázquez and Aizen, 2003). We considered indices to differ between seasons if the $95 \%$ intervals of the $D$-value distributions for dry and wet seasons did not overlap (Gibson et al., 2011). 
We conducted all statistical analyses in R version 2.15.2 (R Core Team, 2012) using the vegan package for multivariate analyses (Oksanen et al., 2012), the nlme package for linear models (Pinheiro et al., 2012) and the bipartite package for network analyses (Dormann et al., 2008).

\section{Results}

Within our herbivore guild, eland had relatively low $\delta^{13} \mathrm{C}$ values characteristic of a more browsing strategy, impala had intermediate $\delta^{13} \mathrm{C}$ values reflecting a mixed feeding strategy and the other species had relatively high $\delta^{13} \mathrm{C}$ values reflecting a strategy on the grazing end of the gradient (Fig $1 \mathrm{~A}$ ). The $\delta^{15} \mathrm{~N}$ values varied less between species, although eland, impala and sable were depleted in $\delta^{15} \mathrm{~N}$ compared to the other species during the dry season (Fig 1B). The mixed feeder impala exhibited a wider isotope niche breadth than the other species, during both wet and dry seasons (Fig 1C). However, there were significant interaction effect of species and season on $\delta^{13} \mathrm{C}$ values $\left(\delta^{13} C F_{5,103}=14.22, p<0.0001\right), \delta^{15} \mathrm{~N}$ values $\left(F_{5,103}=4.19, p<0.002\right)$ and isotope niche breadth $\left(F_{5,103}=9.30, p<0.0001\right)$. Sable $\left(t_{13}=-4.88, p_{a d j}=0.002\right)$ and waterbuck $\left(t_{11}=-\right.$ $3.53, p_{\text {adj }}=0.01$ ) were depleted in ${ }^{13} \mathrm{C}$ in the dry compared to the wet season and the opposite was found for eland $\left(t_{14}=2.81, p_{a d j}=0.03\right)$. Eland $\left(t_{17}=-4.30, p_{a d j}=0.003\right)$ and sable $\left(t_{17}=-3.52, p_{\text {adj }}=0.003\right)$ were depleted in ${ }^{15} \mathrm{~N}$ in the dry compared to the wet season, and sable $\left(\mathrm{t}_{11}=3.52, \mathrm{p}_{\mathrm{adj}}=0.005\right)$ and waterbuck $\left(\mathrm{t}_{15}=2.81, \mathrm{p}_{\mathrm{adj}}=0.01\right) \mathrm{had}$ narrower isotope niche breadth in the wet compared to the dry season.

There was generally a higher degree of isotope overlap in the $\delta^{15} \mathrm{~N}$ networks compared to the $\delta^{13} \mathrm{C}$ ones (Table 1, Fig 2), where the average degree of overlap was significantly lower than random expectations for both dry and wet season for $\delta^{13} \mathrm{C}$ networks but only the dry season was lower than expected for the $\delta^{15} \mathrm{~N}$ networks (Table 1). In both seasons, there was a significant modular interaction pattern in $\delta^{13} \mathrm{C}$ networks (Table 2), with eland constituting an isolated module interacting with the most ${ }^{13} \mathrm{C}$ depleted isotope values with which the rest of herbivores did not interact (Fig 3). During the dry season there were two additional modules; waterbuck and impala with intermediate $\delta^{13} \mathrm{C}$ values, and sable, hartebeest and zebra with the most ${ }^{13} \mathrm{C}$ enriched values. During the wet season we further identified three overlapping modules, one consisting of impala with low to intermediate $\delta^{13} \mathrm{C}$ values, one consisting of sable and waterbuck and another of zebra and hartebeest (Fig 3). Both of these latter modules reflected ${ }^{13} \mathrm{C}$ enriched values. We only found a significant modular pattern in $\delta^{15} \mathrm{~N}$ networks in the dry season (Table 2), with three non-isolated modules in which eland had the most depleted ${ }^{15} \mathrm{~N}$ values, impala and sable had intermediate ${ }^{15} \mathrm{~N}$ values, and hartebeest, zebra and waterbuck had values enriched in ${ }^{15} \mathrm{~N}$ (Fig 3).

The $\delta^{13} \mathrm{C}$ networks showed a non-random nested interaction pattern within the nonisolated modules during both seasons (Table 3), with the isotope niches of hartebeest and sable being nested within those of waterbuck and zebra, which in turn, were nested within the niche of impala (Figure 4). The $\delta^{15} \mathrm{~N}$ networks, however, did not show a significant nestedness either in the dry or wet season (Table 3, Figure 4).

There were no differences in the degree of modularity or nestedness between dry and wet season $\delta^{13} \mathrm{C}$ networks (Tables 2 and 3). Seasonal differences were not evaluated for 
$\delta^{15} \mathrm{~N}$ networks because these did not differ from random expectations for all seasons.

\section{Discussion}

Our results highlighted larger differences in faecal $\delta^{13} \mathrm{C}$ values between species than in $\delta^{15} \mathrm{~N}$ values, and confirm that herbivores aggregated along a browser-grazer gradient. Eland faeces were depleted in ${ }^{13} \mathrm{C}$, followed by intermediate values for impala and the highest values were found for the grazers hartebeest, sable, waterbuck and zebra. These results were supported by the variation in isotope niche breadth, with impala exhibiting the widest niche breadth consistent with its mixed feeding strategy (Meissner et al., 1996; Van Rooyen, 1992) and the other species exhibited narrower isotope niches reflecting more specialised foraging strategies (Gagnon and Chew, 2000; Skinner and Smithers, 1990; Sponheimer et al., 2003b). Our study supports the relative position on the grazer-browser gradient that has previously been indicated by field observations, stomach and faecal contents (Gagnon and Chew, 2000 and Skinner and Smithers, 1990) and by seasonal isotopic dietary values in East and Southern Africa (Cerling et al., 2003; Codron et al., 2005b, 2007 a, b). Our results were further consistent during both wet and dry seasons, supporting that these broad feeding strategies are maintained across seasons.

However, within the broad foraging strategies outlined by $\delta^{13} \mathrm{C}$, our results on $\delta^{15} \mathrm{~N}$ and isotope niche breadth suggest that resource use by some herbivores appears to shift between seasons. Plant growth in South African subtropical savannas is strongly dependent on rainfall, with grass and browse abundance and nutritional quality decreasing after the end of the rainy season (Owen-Smith, 2008). We therefore suggest that these seasonal shifts reflect alterations in foraging strategies in response to precipitation driven changes in available food. Our results suggest that two different strategies occurred to adapt to the limiting dry season, where waterbuck exhibited an increase in niche breadth concurrent with a reduced $\delta^{13} \mathrm{C}$ value, whereas eland appeared to increase their specialization in key resources. We suggest that the low $\delta^{15} \mathrm{~N}$ values for eland during the dry season could reflect a higher consumption of $\mathrm{N}$-fixing plants (Delwiche et al., 1979; Ambrose and De Niro, 1986).

The degree of interaction overlap was lower than random expectations in most of our herbivore-isotope networks, with a partition between herbivores in the use of resources. In particular, for both seasons we found a significant nested within modular pattern of interaction between our herbivores and the different $\delta^{13} \mathrm{C}$ categories. Networks in which resources were defined by their $\delta^{15} \mathrm{~N}$ content were never nested and only significantly modular for the dry season, with mixed feeders and grazers found in modules interacting with lower and higher $\delta^{15} \mathrm{~N}$ values, respectively. This could be a result of the stronger reliance on protein-rich, ${ }^{15} \mathrm{~N}$-depleted leguminous by mixed feeders along with an increased recycling of ${ }^{15} \mathrm{~N}$-depleted urea by grazers during this food limiting season (Ambrose and De Niro, 1986, Sealy et al., 1987). Such modular pattern could have resulted blurred during the rich wet season due to factors affecting $\delta^{15} \mathrm{~N}$ such as water intake by herbivores (Ambrose and De Niro, 1986).

The nested within modular pattern observed in the $\delta^{13} \mathrm{C}$ based networks could reflect ecological characteristics that may have important repercussions for ecosystem 
function and stability (Guimerà et al., 2010). The modular pattern may reflect ecological, physiological, morphological, spatial or temporal barriers in the use of resources by consumers which would structure in sub-guilds, while nested use of resources within modules would reflect optimal foraging strategies within the range of potentially usable resources given the consumers ecology (Lewinsohn and Prado, 2006). Such ecological structuring may prevent disturbances to perturb ecosystems, since they may be contained within modules, and hence improve ecosystem stability (Melián and Bascompte, 2002; Stouffer and Bascompte, 2011). In addition, the nested hierarchy within modules may enhance this stabilizing effect due to increased ecological redundancy within modules (Burgos et al., 2007; Memmott et al., 2004). However, we highlight that a nested pattern could result in competition between specialist and generalist consumers for the shared resources, potentially leading to instability in species diversity within each of the identified modules.

Plant-herbivore interactions have both an antagonistic and a mutualistic component, because plants can either reduce (antagonistic component) or increase (mutualistic component) their relative biomass, abundance and fitness in response to herbivory (Crawley, 1990; De-Val and Crawley, 2005; Owen and Wiegert, 1976). Plant overcompensation in response to herbivory damage, for instance, implies a higher fitness after herbivory as compared to non-eaten plants, which leads to a mutually beneficial interaction for the herbivore consumer and the plant consumed (Agrawal, 2000). Thébault and Fontaine (2010) suggested that ecosystem dynamics and stability coerce antagonistic and mutualistic interactions to opposing interaction structures, with modular patterns enhancing stability on interaction diversity in networks of antagonistic interactions and nested patterns promoting stability in mutualistic networks. Concurrent with these ideas we suggest that the particular observed combination of modular and nested interaction patterns found here reflects the concurrent antagonistic and mutualistic nature of herbivore-plant interactions, where the modular pattern may reflect antagonistic components and the nested pattern mutualistic components of herbivory. Such an interpretation highlights the importance of herbivory for structuring of ecological communities, and for providing ecological stability under environmental perturbations. Such stabilizing effects of herbivory should be capitalized on by conservation actions specifically aiming at preserving ecosystem's functionality in the face of current environmental changes.

\subsection{Study caveats and future research}

Traditionally, stable isotopes have mainly been used to characterize foraging niche breadth, to identify the use of specific resources or habitats, and to trace animal movements (Martínez del Río et al., 2009). Here we expand on these applications to also enable interpretations of ecological interaction structures from stable isotope data (see also Yeakel et al., 2013). Such an approach is highly timely, since it builds on a rapid development both on theoretical and methodological expansion of topological approaches to ecological studies (Miranda et al., 2013), and it expands the scope of ecological information that can be derived from stable isotope studies. Since characterisations of isotope niches encapsulate information both on the taxonomic identity of the resources as well as on the physiology of these resources and the area within which they were assimilated, consumer-isotope network may hold information 
on a wider range of ecological processes than trophic networks derived directly from consumer and resource taxonomic groups. In addition, networks built on stable isotope data as a proxy for used resources facilitate the identification of interactions involving less abundant resources that can be overlooked when using direct observation of consumer-resource interactions in the field.

Despite the fact that species-specific metabolism would be expected to affect the isotope ratios found in faeces and faecal samples represent only the non-digested plant materials, controlled feeding trials and field based studies have shown an agreement between faecal and dietary $\delta^{13} \mathrm{C}$ and $\delta^{15} \mathrm{~N}$ in African herbivores (Codron and Codron, 2009; Codron et al., 2005c; Tieszen et al., 1979). We therefore suggest that our relative differences reflect dietary differences between the herbivore species, either in terms of the taxonomic, geographic, or topographic sources of their food, or in physiological differences between the consumed plants. Both of these contrasts are relevant from an ecological perspective.

Studies analysing trophic networks generally define the interacting entities by aggregating individuals under ontogenic, taxonomic or trophic categories (Miranda et al., 2013). We instead used two non-categorical variables to define the nodes at the resource level. Since much of relevant ecological information is continuous, e.g. body size relationships between predators and prey (Sinclair et al., 2003), we encourage further research on such utilization of categorizations of continuous variables in ecological network analyses. Identifying ways for categorizing resource types in an ecological relevant manner might provide further insights on interaction patterns at finer or wider resolution than the one studied here, where intervals were merely based on average isotope variability within species.

The present and previous studies on species trophic roles (Fortuna et al., 2010; Lewinsohn and Prado, 2006) have found nested within modular patterns in plantanimal and host-parasite interactions. It remains to be studied whether other type of ecological interactions between species and their resources might reveal similar combined patterns of interactions that could emerge as a pervasive property increasing ecosystem stability across interaction types, temporal and spatial scales and levels of biological organization. In addition, the present study quantified interactions between herbivores and plants that likely comprised both antagonistic and mutualistic components, depending on plant response to herbivory. If our interpretation that the concurrent antagonistic and mutualistic characteristics of herbivore caused the combined modular and nested interaction patterns is correct, an identification of the nodes involved in antagonistic vs. mutualistic interactions would be required to fully understand the effects of modularity and nestedness on the stability of ecological communities that contain both types of interactions (Sauve et al., 2014).

\section{Acknowledgements}

The authors are grateful to North West Parks and Tourism Board and Kgaswane Mountain Reserve management, which provided free access and accommodation within the reserve premises and facilitated our work at all times. Drs. Stephan Woodborne and Grant Hall supervised the stable isotope analyses at the Council for 
Scientific and Industrial Research, Pretoria. Dr. Sally Archibald provided useful insights during early stages of the study. MM was supported by a Free-standing Postdoctoral Fellowship co-funded by the National Research Foundation and the University of the Witwatersrand, and a Claude Leon Postdoctoral Fellowship. FP received financial support from the University of the Witwatersrand; FD from University of Pretoria and the National Research Foundation. Project funding was provided by the University of the Witwatersrand.

\section{References}

Agrawal AA (2000) Overcompensation of plants in response to herbivory and the by-product benefits of mutualism. Trends Plant Sci. 5: 309-313

Allesina S, Pascual M (2008) Network structure, predator-prey modules, and stability in large food webs. Theor. Ecol. 1: 55-64

Ambrose SH (1991) Effects of diet, climate and physiology on nitrogen isotope abundances in terrestrial food webs. J. Archaeol. Sci. 18:293-317

Ambrose SH, De Niro MJ (1986) The isotopic ecology of East African mammals. Oecologia 69: 395-406

Barber M (2007) Modularity and community detection in bipartite networks. Phys. Rev. E 76: 1-9

Bascompte J, Jordano P, Melian CJ, Olesen JM (2003) The nested assembly of plant-animal mutualistic networks. Proc. Natl. Acad. USA 100: 9383-9387

Bastolla U, Fortuna MA, Pascual-García A, Ferrera A, Luque B, Bascompte J (2009) The architecture of mutualistic networks minimizes competition and increases biodiversity. Nature 458: 1018-1021

Benjamini Y, Hochberg Y (1995) Controlling the false discovery rate: a practical and powerful approach to multiple testing. J. R. Stat. Soc., Series B 57: 289-300

Buitenwerf R, Swemmer AM, Peel MJS (2011) Long-term dynamics of herbaceous vegetation structure and composition in two African savanna reserves. J. Appl. Ecol. 48: 238-246

Burgos E, Ceva H, Perazzo RPJ, Devoto M, Medan D, Zimmermann M, Delbue AM (2007) Why nestedness in mutualistic networks? J. Theor. Biol. 249: 307-313

Cerling TE, Harris JM, Passey BH (2003) Diets of East African bovidae on stable isotope analysis. J. Mammal. 84: 456-470

Clauset A, Moore C, Newman MEJ (2008) Hierarchical structure and the prediction of missing links in networks. Nature 453: 98-101

Codron D, Codron J (2009) Reliability of $\delta^{13} \mathrm{C}$ and $\delta^{15} \mathrm{~N}$ in faeces for reconstructing savana herbivore diet. Mamm Biol 74: 36-48

Codron J, Codron D, Lee-Thorp JA, Sponheimer M, Bond WJ, de Ruiter D, Grant R (2005a) Taxonomic, anatomical, and spatio-temporal variations in the stable carbon and nitrogen isotopic compisitions of plants from an African savanna. J. Archaeol. Sci. 32: 1757-1772

Codron D, Codron J, Lee-Thorp JA, Sponheimer M, de Ruiter D (2005b) Animal diets in the Waterberg based on stable isotopic composition of faeces. S. Afr. J. Wildl. Res. 35: 43-52

Codron D, Codron J, Sponheimer M, Lee-Thorp JA, Robinson T, Grant CC, de Ruiter D (2005c) Assesing diet in savanna herbivores using stable carbon isotope ratios of faeces. Koedoe 48: 115-124

Codron D, Codron J, Lee-Thorp JA, Sponheimer M, de Ruiter D, Sealy J, Grant R, Fourie N (2007a) Diets of savanna ungulates from stable carbon isotope composition of faeces. J. Zool. 273: 21-29

Codron D, Lee-Thorp JA, Sponheimer M, Codron J (2007b) Stable carbon isotope reconstruction of ungulate diet changes through the seasonal cycle. S Afr. J. Wildl. Res. 37: 117-125

Crawley MJ (1990) Rabbit grazing, plant competition and seedling recruitment in acid grassland. J. Appl. Ecol. 27: 803-820

Dalerum F, Angerbjorn A (2005) Resolving temporal variation in vertebrate diets using naturally occurring stable isotopes. Oecologia 144: 647-658

Dalerum F, Cameron EZ, Kunkel KE, Somers MJ (2012a) Interactive effects of species richness and species traits on functional diversity and redundancy. Theor. Ecol. 5: 129-139

Dalerum F, Perbro A, Magnusdottir R, Hersteinsson P, Angerbjorn A (2012b) The influence of coastal access on isotope variation in Icelandic arctic foxes. PLoS ONE 7: e32071

Del-Val EK, Crawley MJ (2005) Are grazing increaser species better tolerators than decreasers? An experimental assessment of defoliation tolerance in eight British grassland species. J. Ecol. 93:1005-1016

Delwiche CC, Zinke PJ, Johnson CM, Virginia RA (1979) Nitrogen isotope distribution as a presumptive indicator of nitrogen fixation. Bot. Gaz. 140: 565-569 
Dobson A (2009) Food-web structure and ecosystem services: insights from the Serengeti. Philos. Trans. R. Soc. B 364: 1665-1682

Dormann CF, Blüthgen N, Fründ J, Gruber B (2009) Indices, graphs and null models: analyzing bipartite ecological networks. Open Ecol. J. 2: 7-24

Dormann CF, Gruber B, Fruend J (2008) Introducing the bipartite package: analysing ecological networks. R news Vol 8/2, 8 - 11

Dormann CF, Strauss R (2013) Detecting modules in quantitative bipartite networks: the QuaBiMo algorithm. arXiv:1304.3218[q-bio.QM]

Elton CS (1927) Animal ecology. Sidgwick and Jackson, London

Evans RD (2001) Physiological mechanisms influencing plant nitrogen isotope composition. Trends Plant Sci. 6: 121-126

Farquhar GD, Ehleringer JR, Hubik KT (1989) Carbon isotope discrimination and photosynthesis. Annu. Rev. Plant Physiol. Plant Mol. Biol. 40: 503-537

Fortuna MA, Stouffer DB, Olesen JM, Jordano P, Mouillot, D, Krasnov BR, Poulin R, Bascompte J (2010) Nestedenss versus modularity in ecological networks: two sides of the same coin? J. Anim. Ecol. 79: 811-817

Fritz H, Loison A (2006) Large herbivores across biomes, in: Danell K, Bergstrom R, Duncan P, Pastor J (Eds.), Large herbivore ecology, ecosystem dynamics and conservation. Cambridge University, Cambridge, pp 19-49

Gagnon M, Chew AE (2000) Dietary preferences in extant African Bovidae. J. Mammal. 81: 490-511

Galeano J, Pastor JM, Iriondo, JM (2008) Weighted-Interaction Nestedness Estimator (WINE): a new estimator to calculate over frequency matrices. arXiv 0808.3397v1 [physics.bio-ph]

Gibson RH, Knott B, Eberlein T, Memmot J (2011) Sampling method influences the structure of plantpollinator networks. Oikos 120: 822-831

Gómez JM, Verdú M, Perfectti F (2010) Ecological interactions are evolutionarily conserved across the entire tree of life. Nature 465: 918-922

Guimerà R, Stouffer DB, Sales-Pardo M, Leicht A, Newman MEJ, Amaral LAN (2010) Origin of compartmentalization in food webs. Ecology 91: 2941-2951

Handley LL, Raven JA (1992) The use of natural abundance of nitrogen isotopes in plant physiology and ecology. Plant Cell Environ. 15: 965-985

Harary F (1961) Who eats whom? Gen. Syst. 6: 41-44

Heaton THE (1987) ${ }^{15} \mathrm{~N} /{ }^{14} \mathrm{~N}$ ratios of plants in South Africa and Namibia: relationship to climate and coastal/saline environments. Oecologia 74: 236-246

Hofmann RR, Stewart DRM (1972) Grazer or browser: a classification based on the stomach structure and feeding habits of East African ruminants. Mammalia 36: 226-240

Holling CS (1973) Resilience and stability of ecological systems. Annu. Rev. Ecol. Evol Syst. 4: 1-23

Horn HS (1966) Measurement of "overlap" in comparative ecological studies. Am. Nat. 100: 419-424

Hunter MD, Price PW (1992) Playing chutes and ladders: heterogeneity and the relative roles of bottomup and top-down forces in natural communities. Ecology 73: 724-732

Iason GR, van Wieren SE (1999) Digestive and ingestive adaptations of mammalian herbivores to low quality forage, in: Olff H, Brown VK, Brent R (Eds.) Herbivores: between plants and predators. Proceedings of the Symposium of the British Ecological Society, Blackwell Scientific Publications, Oxford, pp. 337-369

Ings TC, Montoya JM, Bascompte J, Blüthgen N, Brown L, Dormann CF, Edwards F, Figueroa D, Jacob U, Jones JI, Lauridsen RB, Ledger ME, Lewis HM, Olesen JM, van Veen FJF, Warren PH, Woodward G (2009) Ecological networks-beyond food webs. J. Anim. Ecol. 78: 253-269

IPCC (2013) Annex I: Atlas of Global and Regional Climate Projections in: van Oldenborgh GJ, Collins M, Arblaster J, Christensen JH, Marotzke J, Power SB, Rummukainen M, Zhou T (Eds.) Climate Change 2013: The Physical Science Basis, in: Stocker TF, Qin D, Plattner G-K, Tignor M, Allen,SK, Boschung J, Nauels A, Xia Y, Bex V, Midgley PM (Eds.) Contribution of Working Group I to the Fifth

Kirtman B, Power SB, Adedoyin JA, Boer GJ , Bojariu R, Camilloni I, Doblas-Reyes GJ, Fiore AM, Kimoto M, Meehl GA, Prather M, Sarr A, Schär C, Sutton R, van Oldenborgh GJ, Vecchi G, Wang HJ (2013) Assessment Report of the Intergovernmental Panel on Climate Change Cambridge University Press, Cambridge, United Kingdom and New York.Near-term Climate Change: Projections and Predictability, in: Stocker TF, Qin D, Plattner G-K, Tignor M, Allen,SK, Boschung J, Nauels A, Xia Y, Bex V, Midgley PM (Eds.) Contribution of Working Group I to the Fifth Assessment Report of the Intergovernmental Panel on Climate Change Cambridge University Press, Cambridge, United Kingdom and New York.

Krebs CJ (1989) Ecological Methodology. Harper Collins, New York 
Laliberté E, Tylianakis JM (2010) Deforestation homogenizes tropical parasitoid-host networks. Ecology 91: $1740-1747$

Layman CA, Arrington DA, Montaña CG, Post DM (2007) Can stable isotope ratios provide for community-wide measures of trophic structure? Ecology 88: 42-48

Lewinsohn TM, Prado PI (2006) Structure in plant-animal interaction assemblages. Oikos 113: 174-184

Low AB, Rebelo AG (1996) Vegetation of South Africa, Lesotho and Swaziland. Department of Environmental Affairs and Tourism. Pretoria, South Africa

Manly BFJ (1997) Randomization, bootstrap, and Monte Carlo methods in biology. $2^{\text {nd }}$ ed. Chapman and Hall

Martínez del Río C, Wolf N, Carleton SA, Gannes LZ (2009) Isotopic ecology ten years after a call for more laboratory experiments. Biol. Rev. 84: 91-111

May RM (1973) Stability and complexity in model ecosystems. Princeton University Press, Princeton

Meissner HH, Pieterse E, Potgieter JHJ (1996) Seasonal food selection by male impala Aepyceros melampus in two habitats. S. Afr. J. Wildl. Res. 26: 56-63

Melián CJ, Bascompte J (2002) Complex networks: two ways to be robust? Ecol. Lett. 5: 705-708

Memmott J, Waser NM, Price MV (2004) Tolerance of pollination networks to species extinctions. Proc. R. Soc. Lond. B 271: 2605-2611

Memmott J, Craze PG, Waser NM, Price MV (2007) Global warming and the disruption of plantpollinator interactions. Ecol. Lett. 10: 710-717

Miranda M, Parrini, F, Dalerum F (2013) A categorization of recent network approaches to analyse trophic interactions. Meth. Ecol. Evol. 4: 897-905

Nel HP (2000) Ecological management objectives and monitoring procedures for Rustenburg Nature Reserve, North West Province. Master thesis, Centre for Wildlife Management, Faculty of Natural and Agricultural Sciences, University of Pretoria. Pretoria, South Africa.

Nel P, Knoop C, Seitlhamo W, Tshenkeng P (2011) Animal population estimates for protected areas in the North West Province. Scientific Report, North West Parks and Tourism Board, Mafikeng

Oksanen J, Blanchet FG, Kindt R, Legendre P, Minchin PR, O'Hara RB, Simpson GL, Solymos P, Henry M, Stevens H, Wagner H (2012) vegan: Community Ecology Package. R package version 2.0-5. http://CRAN.R-project.org/package=vegan. Accessed 2013 Jul 23

Owen D, Wiegert R (1976) Do consumers maximize plant fitness. Oikos 27: 488-492

Owen-Smith N (1997) Distinctive features of the nutritional ecology of browsing versus grazing ruminants. J. Mammal Biol. 62: 176-191

Owen-Smith N (2008) The comparative population dynamics of browsing and grazing ungulates, in: Gordon IJ, Prins HHT (Eds.) The ecology of browsing and grazing. Ecological Studies 195. Springer, Berlin Heidelberg, pp. 149-177

Pinheiro JC, Bates DM (2000) Mixed effect models in S and S-plus. Springer-Verlag, New York

Pinheiro J, Bates D, DebRoy S, Sarkar D, the R Development Core Team (2012) nlme: linear and nonlinear mixed effects models. R package version 3.1-105

Prado PI, Lewinsohn TM (2004) Compartments in insect-plant associations and their consequences for community structure. J. Anim. Ecol. 73: 1168-1178

R Core Team (2012) R: A language and environment for statistical computing. R Foundation for Statistical Computing, Vienna, Austria. ISBN 3-900051-07-0, URL http:/www.R-project.org/

Robbins CT (1993) Wildlife feeding and nutrition. 2nd edition. Academic Press Inc., New York

Rutherford MC, Midgley GF, Bond WJ, Powrie LW, Roberts R, Allsopp J (1999), in: Kiker G (Ed.) Climate change impacts in southern Africa. Report to the National Climate Change Committee, Department of Environment Affairs and Tourism, Pretoria

Sauve AMC, Fontaine C, Thébault E (2014) Structure-stability relationships in networks combining mutualistic and antagonistic interactions. Oikos 123: 378-384

Schulz E, Kaiser TM (2013) Historical distribution, habitat requirements and feeding ecology of the genus Equus (Perissodactyla). Mammal Rev. 43: 111-123

Sealy JC, Van der Merwe NJ, Lee-Thorp JA, Lanham JL (1987) Nitrogen isotopic ecology in southern Africa: implications for environmental and dietary tracing. Geochim. Cosmochim. Acta 51: 27072717

Sinclair ARE, Mduma SAR, Brashares JS (2003) Patterns of predation in a diverse predator-prey system. Nature 425:288-290

Skinner JD, Smithers RHN (1990) The mammals of the southern African subregion. 2nd ed. University of Pretoria, Pretoria

Smith TM, Smith RL (2012) Elements of Ecology. $8^{\text {th }}$ ed. Benjamin Cummings, Boston

Sponheimer M, Robinson T, Ayliffe L, Passey B, Roeder B, Shipley L, López E, Cerling T, Dearing D, Ehleringer J (2003a) An experimental study of carbon-isotope fractionation between diet, hair, and 
faeces of mammalian herbivores. Can. J. Zool. 81:871-876

Sponheimer M, Lee-Thorp J, de Ruiter DJ, Smith JM, van der Merwe NJ, Reed K, Grant CC, Ayliffe LK, Robinson TF, Heidelberger C, Marcus W (2003b) Diets of southern African bovidae: stable isotope evidence. J. Mammal. 84: 471-479

Stouffer DB, Bascompte J (2011) Compartmentalization increases food-web persistence. Proc. Natl. Acad. U.S.A. 108: 3648-3652

Sugihara G (1984) Graph theory, homology and food webs. Am. Math. Soc. 30: 83-101

Thébault E, Fontaine C (2010) Stability of ecological communities and the architecture of mutualistic and trophic networks. Science 329: 853-856

Tieszen LL, Hein D, Qvortrup SA, Troughton JH, Imbamba SK (1979) Use of $\delta^{13} \mathrm{C}$ values to determine vegetation selectivity in East African herbivores. Oecologia 37: 351-359

Van der Merwe J, Marshal JP (2012) Hierarchical resource selection by impala in a savanna environment. Austral Ecol. 37: 401-412

Van Rooyen AF (1992) Diets of impala and nyala in two game reserves in Natal, South Africa. South Afr. J. Wildl. Res. 22: 98-101

Vázquez DP, Aizen MA (2003) Null model analyses of specialization in plant-pollinator interactions. Ecology 84: 2493 -2501

Watson LH, Owen-Smith N (2000) Diet composition and habitat selection of eland in semi-arid shrubland. Afr. J. Ecol. 38: 130-137

Yeakel JD, Guimaraes PR, Bocherens H, Koch PL (2013) The impact of climate change on the structure of Pleistocene food webs across the mammoth steppe. Proc. R. Soc. B 280: 20130239 


\section{TABLES}

Table 1. Horn-Morisita indices of niche overlap between herbivores in interaction networks based on $\mathrm{C}$ and $\mathrm{N}$ isotopes for each season, average niche overlap in null models, and z-score values of observed degree of overlap as compared to null model distributions. P-values lower than 0.05 were interpreted as showing that the observed degree of niche overlap was significantly different from the null network values.

\begin{tabular}{cccccc}
\hline network & season & niche overlap & average niche overlap in null models & z-score & P-value \\
\hline$\delta^{13} \mathrm{C}$ based & dry & 0.38 & 0.76 & -7.11 & $<0.001$ \\
& wet & 0.47 & 0.83 & -7.54 & $<0.001$ \\
$\delta^{15} \mathrm{~N}$ based & dry & 0.57 & 0.71 & -2.21 & 0.01 \\
& wet & 0.68 & 0.78 & -1.63 & 0.05 \\
\hline
\end{tabular}

Table 2. Modularity values of networks based on $\mathrm{C}$ and $\mathrm{N}$ isotopes for each season, and z-score values of observed modularity as compared to null model distributions. Pvalues lower than 0.05 were interpreted as showing that the observed modularity was significantly different from the null network values. We also report lower and higher limits for $95 \%$ confidence intervals $(\mathrm{Cl})$ for the distributions of D-values calculated to compare significant indices across seasons. Overlapping $\mathrm{Cls}$ indicate lack of differences across seasons between compared networks.

\begin{tabular}{lcccccc}
\hline network & season & modularity & z-score & P-value & lower 95\% Cl limit & higher 95\% Cl limit \\
\hline${ }^{13} \mathrm{C}$ based & dry & 0.47 & 7.43 & $<0.001$ & -0.29 & -0.17 \\
& wet & 0.43 & 6.88 & $<0.001$ & -0.25 & -0.14 \\
${ }^{15} \mathrm{~N}$ based & dry & 0.29 & 2.51 & 0.006 & & \\
& wet & 0.23 & 1.36 & 0.09 & & \\
\hline
\end{tabular}


Table 3. Descriptors of nested patterns across seasons, excluding the isolated modules. We report WIN, WINE, z-score and P-value of observed values as compared to null model distributions. P-values lower than 0.05 were interpreted as showing that the observed nestedness was significantly different from the null network values. We also report lower and higher limits for $95 \%$ confidence intervals $(\mathrm{Cl})$ for the distributions of $\mathrm{D}$-values calculated for significant indices. Overlapping $\mathrm{Cls}$ indicate lack of differences across seasons between compared networks.

\begin{tabular}{lccccccc}
\hline network & season & WIN & WINE & z-score & P-value & lower 95\% Cl limit & higher 95\% Cl limit \\
\hline${ }^{13} \mathrm{C}$ based & dry & 0.52 & 0.44 & 2.55 & 0.005 & -0.14 & -0.02 \\
& wet & 0.72 & 0.69 & 4.25 & $<0.0001$ & -0.25 & -0.09 \\
${ }^{15} \mathrm{~N}$ based & dry & 0.29 & -0.1 & -0.55 & 0.71 & & \\
& wet & 0.31 & 0.06 & 0.3 & 0.38 & & \\
\hline
\end{tabular}




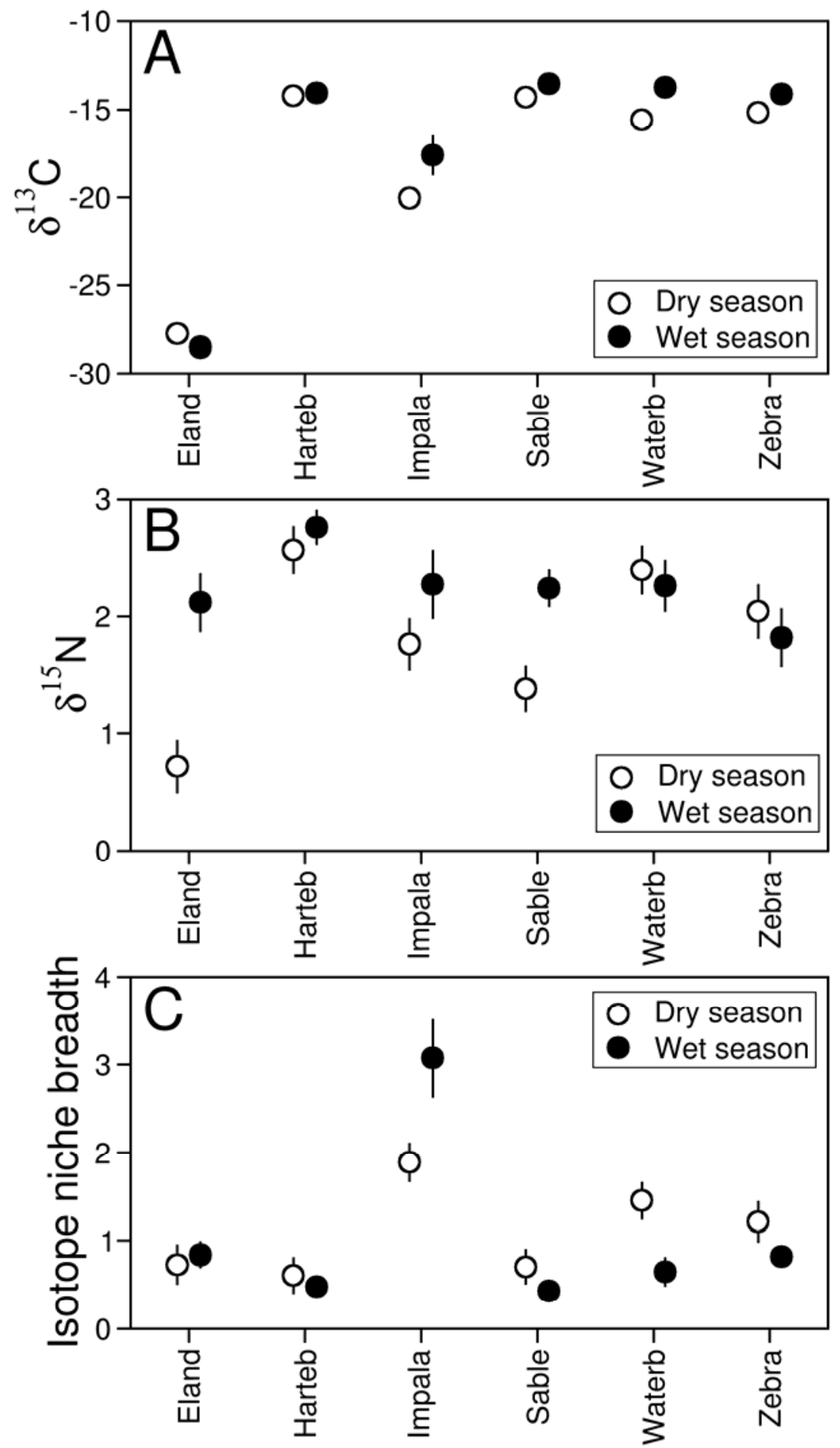

Fig. 1 Mean $\pm 1 S E$ of $(a) \delta^{13} \mathrm{C}$, (b) $\delta^{15} \mathrm{~N}$ and (c) isotope niche breadth of faecal samples for each of the study species in dry and wet seasons. Isotope niche breath was quantified as the Euclidean distance of each sample to group centroids in a two dimensional isotope space created by $\delta{ }^{13} \mathrm{C}$ and $\delta{ }^{15} \mathrm{~N}$. 


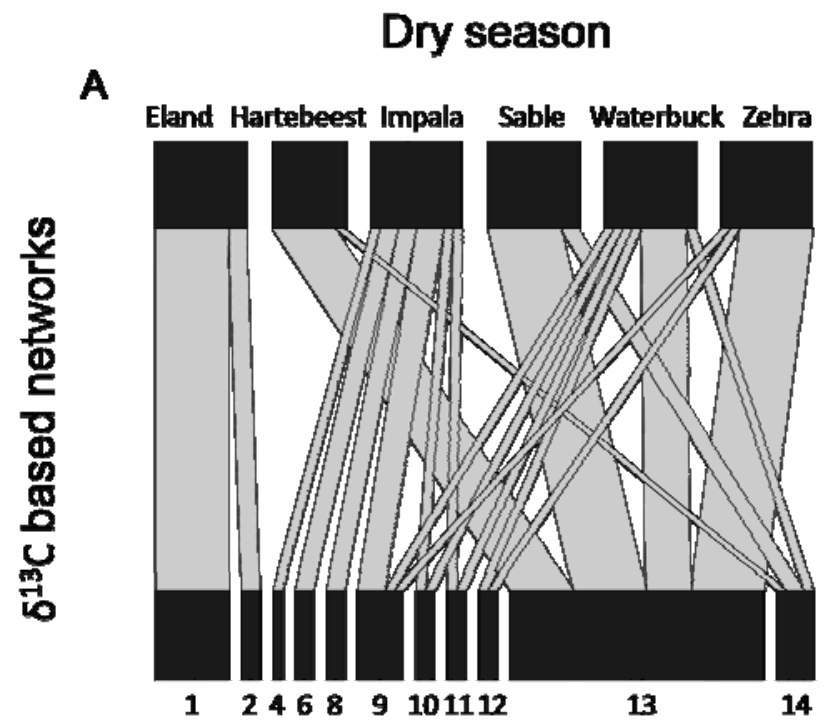

Number of SD in $8^{13} \mathrm{C}$ above the lowest value (-28.39)

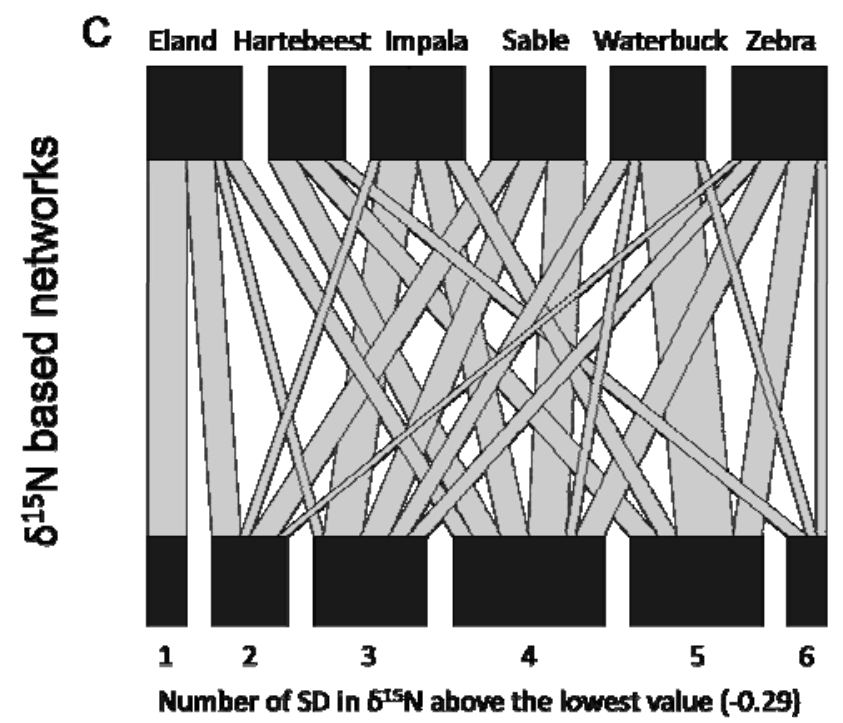

Wet season

B

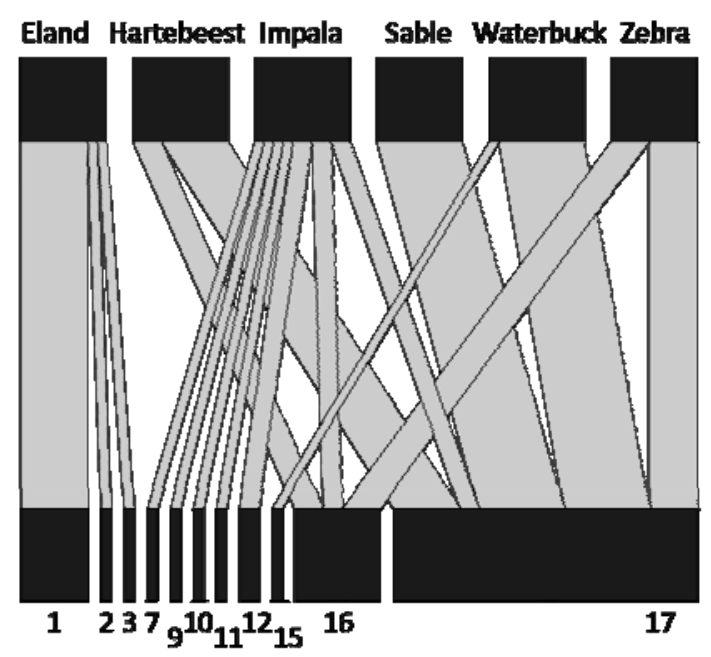

Number of SD in $\delta^{13} \mathrm{C}$ above the lowest value (-29.18)

D

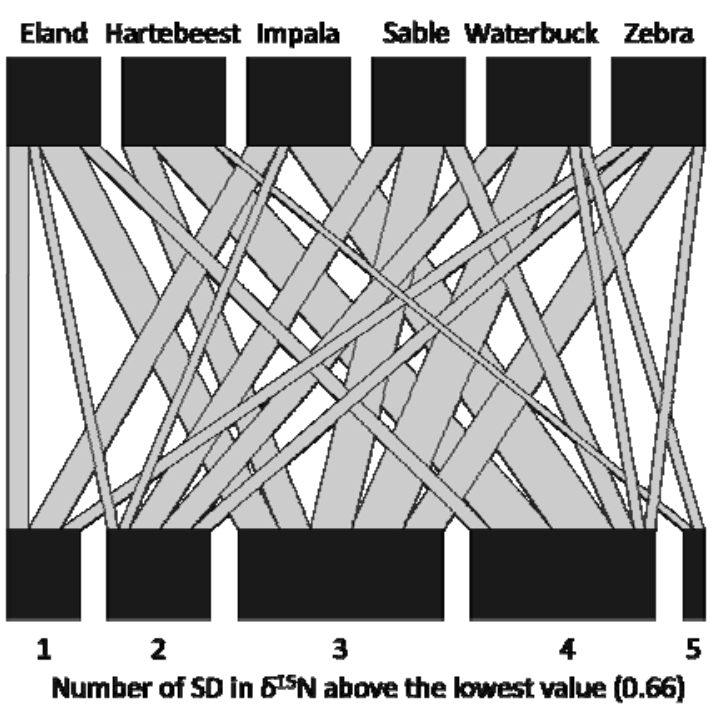

Fig. 2 Bipartite networks of herbivore-isotope categories interactions across seasons. Increasing resource categories indicate increased values of $\delta^{13} \mathrm{C}$ and $\delta^{15} \mathrm{~N}$, for $\delta^{13} \mathrm{C}$ based and $\delta^{15} \mathrm{~N}$ based networks, respectively. The bar width is proportional to the number of interactions in which the consumer/resource is involved, and the link width is proportional to the interaction frequency 
Dry season

A
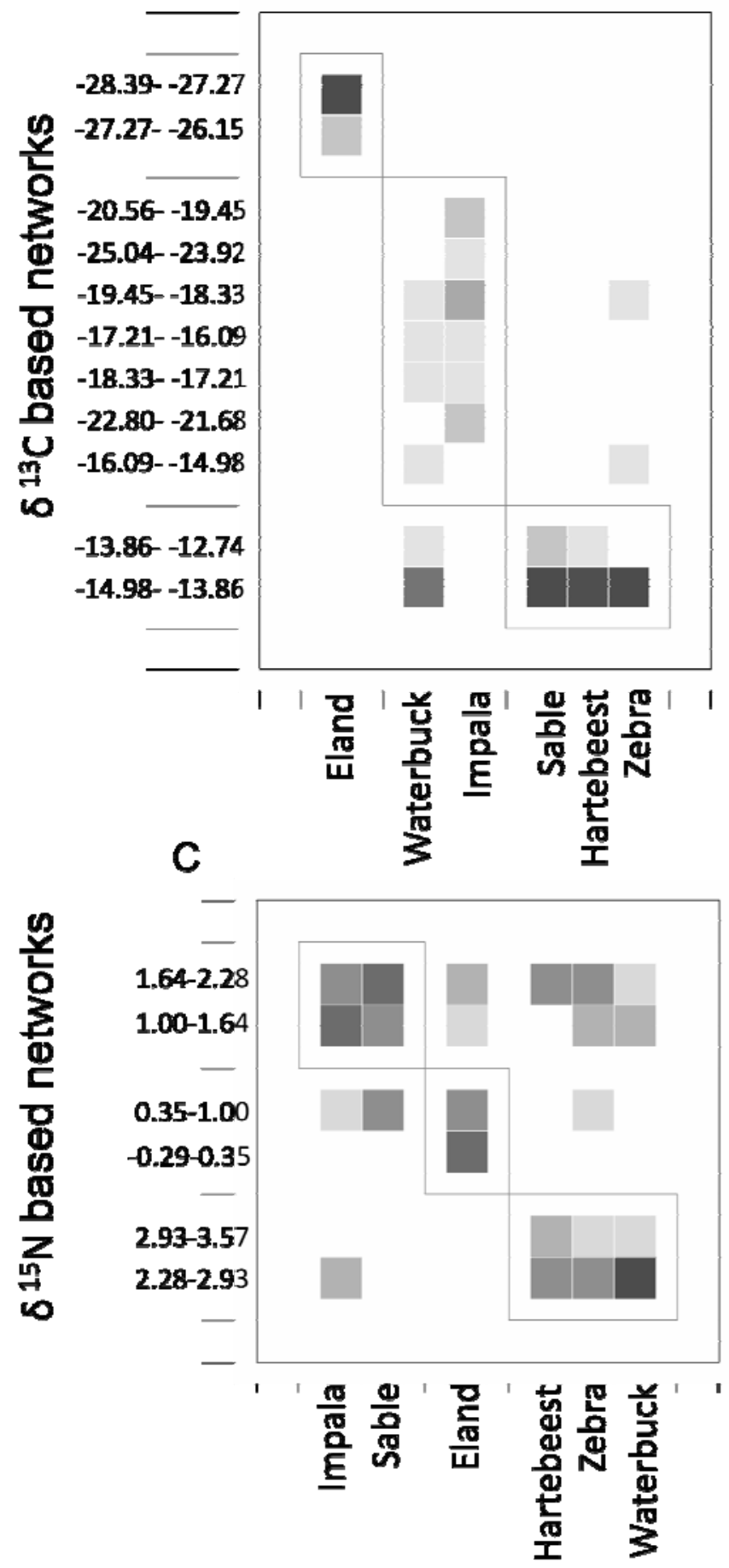

Wet season

B
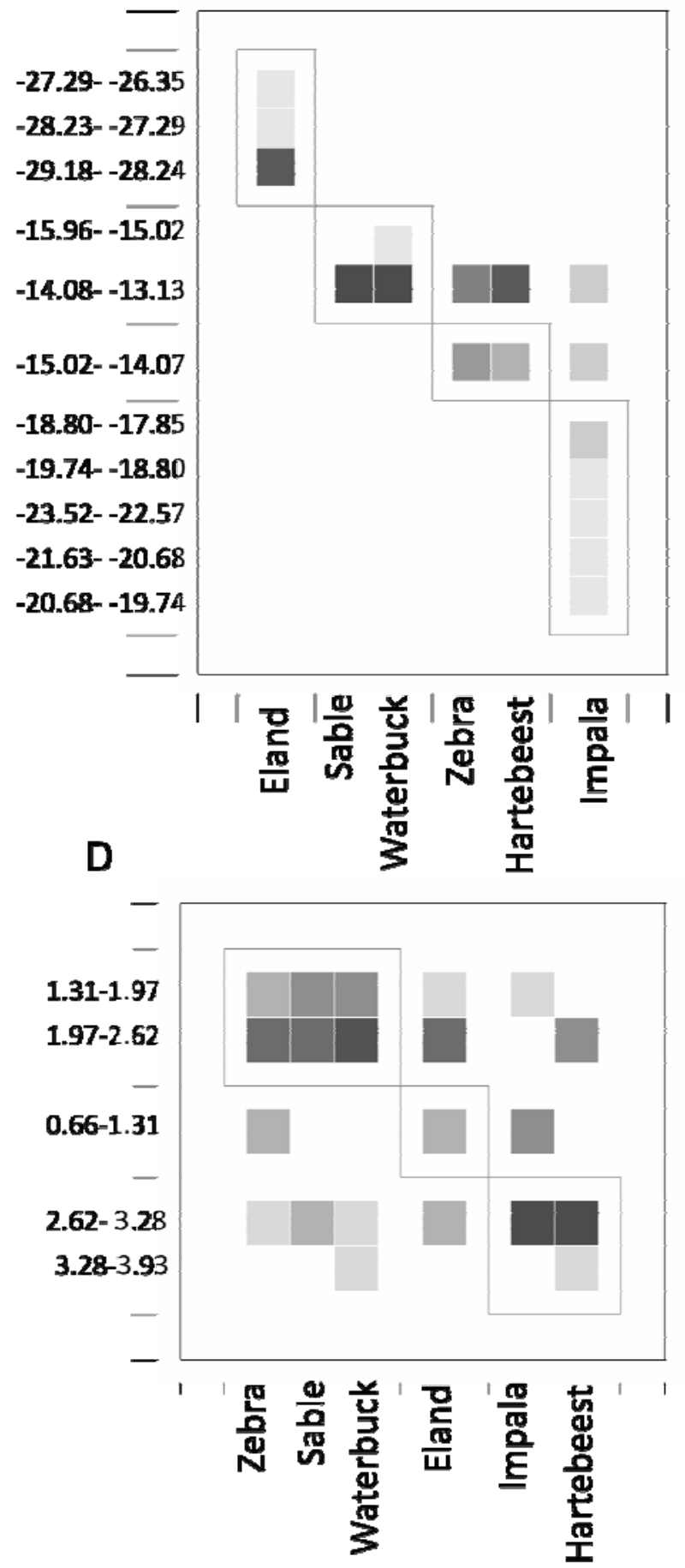

Fig. 3 Visualization of modules in herbivore-resource interaction matrices. Resource categories indicate ranges of $\delta{ }^{13} \mathrm{C}$ and $\delta{ }^{15} \mathrm{~N}$, for $\delta{ }^{13} \mathrm{C}$ based and $\delta{ }^{15} \mathrm{~N}$ based networks, respectively. Filled squares indicate interaction between the nodes in the respective row and columns and darker filling indicates higher interaction frequency. Boxes delineate the modules identified with the QuaBiMo algorithm 
Dry season

A

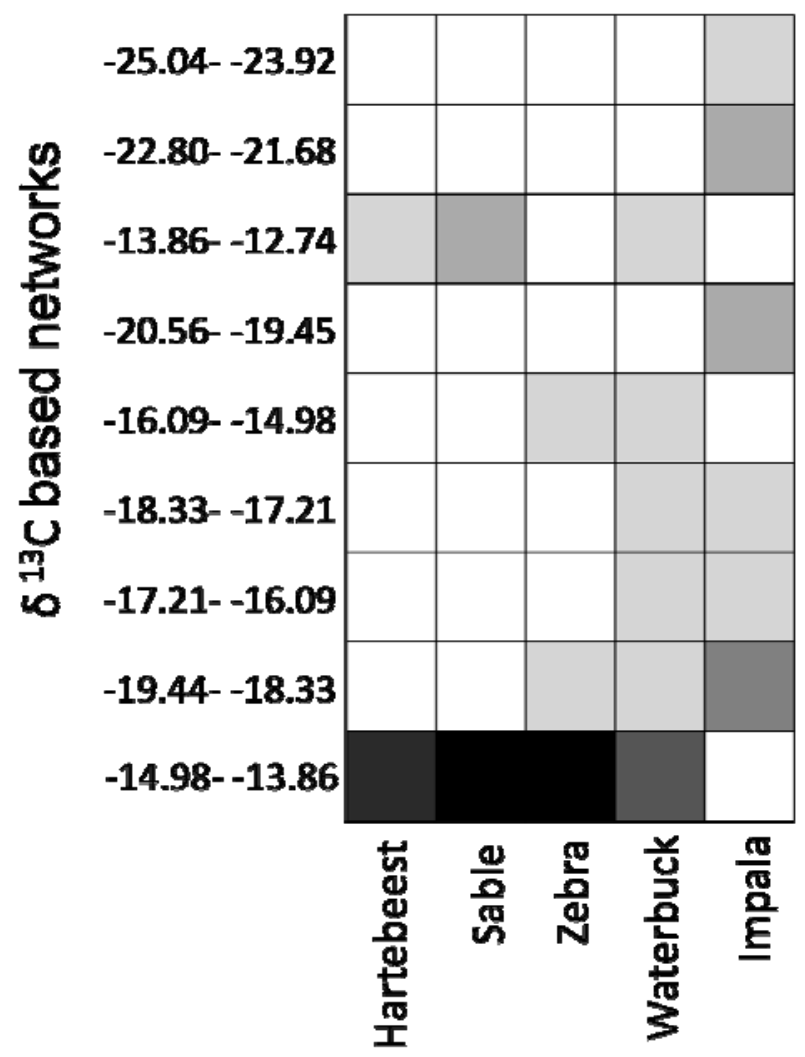

C

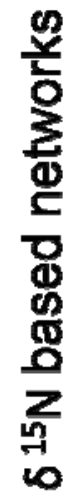

Wet season

B

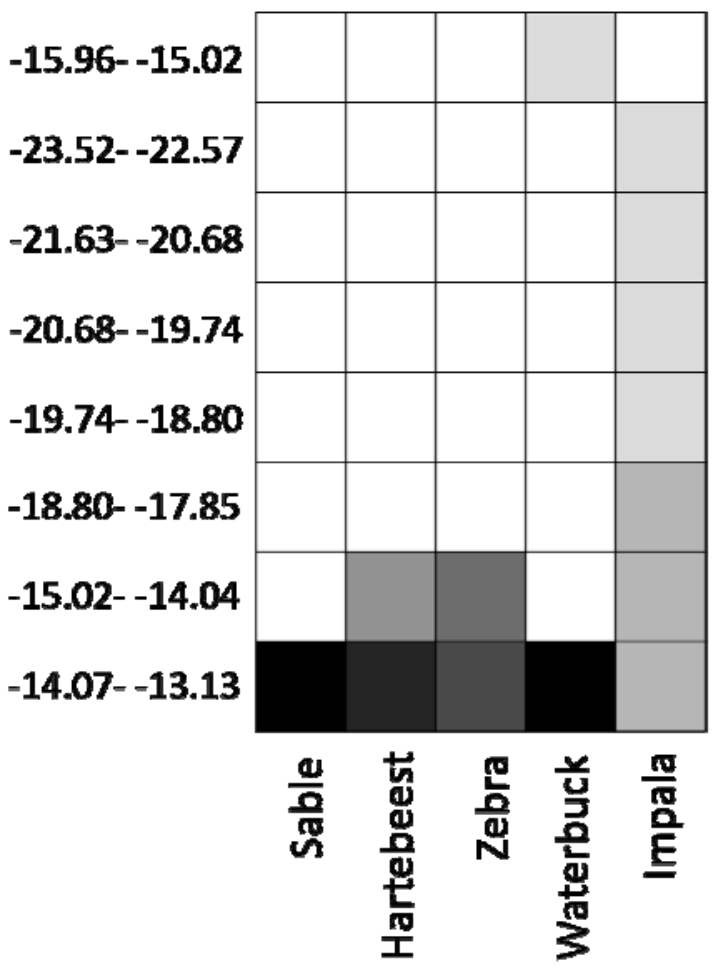

D

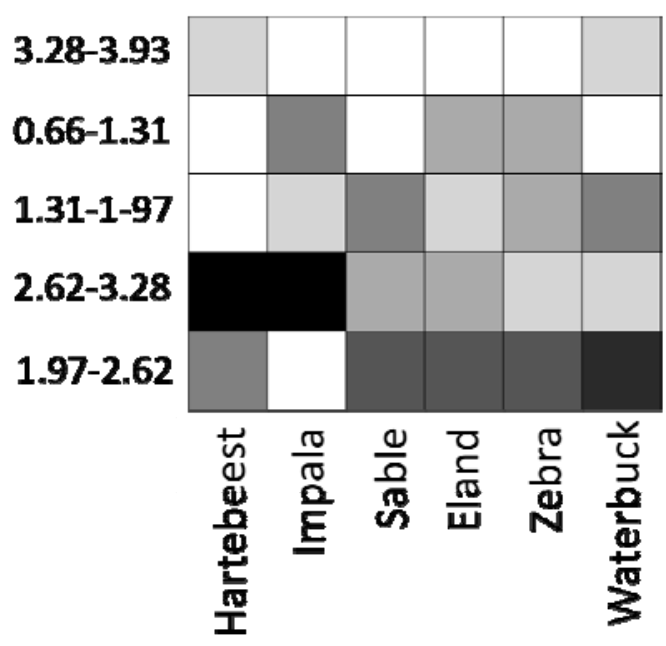

Fig. 4 Visualization of nested patterns in herbivore-resource interaction matrices for each element and season. Rows and columns are arranged from top to bottom and from left to right, respectively, in ascending order according to the number of links. Resource categories indicate ranges of $\delta{ }^{13} \mathrm{C}$ and $\delta{ }^{15} \mathrm{~N}$, for $\delta{ }^{13} \mathrm{C}$ based and $\delta{ }^{15} \mathrm{~N}$ based networks, respectively. Filled squares indicate interaction between the nodes in the respective row and columns and darker filling indicates higher interaction frequency 


\title{
Supplementary material
}

Interaction patterns within a multi-herbivore assemblage derived from stable isotopes

\author{
Miranda M, Dalerum F, Parrini F
}

Appendix S1. Equation used for calculating Horn-Morishita index $\mathrm{C}_{\mathrm{H}}$

$$
C_{H}=\frac{1-\left[2 \sum_{i=1}^{S} x_{i}^{*} y_{i}\right]}{\left(\frac{\sum_{i=1}^{S} x_{i}^{2}}{\left(\sum_{i=1}^{S} x_{i}\right)^{2}}+\frac{\sum_{i=1}^{S} y_{i}^{2}}{\left(\sum_{i=1}^{S} y_{i}\right)^{2}}\right)} *\left(\sum_{i=1}^{S} x_{i}\right) *\left(\sum_{i=1}^{S} y_{i}\right)
$$

where $\mathrm{S}$ is the total number of resource categories and $x_{i}$ and $y_{i}$ are the frequencies of use of the ith resource category by consumer $x$ and $y$, respectively.

Appendix S2. Equation and description of calculations of $Q$ modularity index

$$
Q=(1 / 2 N) \sum_{i j}\left(A_{i j}-K_{i j}\right) \partial\left(m_{i}, m_{j}\right)
$$

where $\mathrm{N}$ is the total number of observed links in the network and Aij is the normalised interaction matrix between consumers and resources, it is normalised so that the sum of all link strengths equals to 1 . Kij is the normalised null model matrix (see Dormann and Strauss 2013), $m_{i}$ and $m_{j}$ are the modules to which species $i$ and $j$ are respectively 
assigned, and the indicator function $\mathrm{d}\left(\mathrm{m}_{\mathrm{i}}, \mathrm{m}_{\mathrm{j}}\right)$ equals 1 when $\mathrm{m}_{\mathrm{i}}=\mathrm{m}_{\mathrm{j}}$, being otherwise equal to 0 .

The QuaBiMo algorithm builds a dendrogram of interacting species in which distances between species that are more likely to interact are shorter that between species that interact less. Dendrogram branches are randomly swapped through a Simulated Annealing-Monte Carlo procedure and $Q$ is computed for each generated dendrogram (Danon et al. 2005; Guimerá and Amaral 2005). When the modularity of a dendogram is higher than that of the previous one, this is recorded as the current solution. When the modularity of a dendrogram is lower than in the previous one, the new dendrogram is accepted as the new solution with a given probability. When $Q$ does not change over a a pre-determined number of swaps (in our case $10^{6}$, following Dormann and Strauss 2013 ), that value is assumed to represent the modularity of that network.

Danon L, Diaz-Guilera A, Duch J, Arenas A (2005) Comparing community structure identification. J. Stat. Mech. Theor. Exp., art no P09008

Dormann CF, Strauss R (2013) Detecting modules in quantitative bipartite networks: the QuaBiMo algorithm. arXiv:1304.3218[q-bio.QM]

Guimerà R, Amaral LAN (2005) Functional cartography of complex metabolic networks. Nature 433: 895900 
Appendix S3. Equation and description of calculations of WIN and WINE nestedness indices

$$
W I N=\frac{1}{N}\left(\sum_{i, j} \frac{a_{i j}}{\sum_{i=1}^{N c} a_{i j}} * x_{i}\right)+\left(\sum_{i, j} \frac{a_{i j}}{\sum_{j=1}^{N r} a_{i j}} * y_{i}\right)
$$

where aij is the link strength between the ith consumer and the jth resource in the interaction matrix. $\mathrm{Nc}$ and $\mathrm{Nr}$ are the number of rows and columns of the interaction matrix, respectively, and xi and yi are the positions of the elements of the interaction matrix when the packed matrix is mapped into a Cartesian space and rescaled to the unit square (Galeano et al. 2008).

WIN is calculated by ordering the rows of the interaction matrix from top to bottom and columns from left to right, in ascending order according to the number of links. WIN is then calculated as the mean weighted Manhattan distance from each of the matrix cells containing a link to the cell corresponding to the intersection of the row and columns with the lowest link number, where the weights reflect the interaction strength between consumers and resources (see Galeano et al. 2008 for detailed descriptions of calculations).

For ease of interpretation, we have presented nestedness values as the weighted nestedness estimator (WINE) that ranges from 0 (random structure) to 1 (total nestedness). WINE is calculated by normalizing the observed WIN with the average WIN of random matrices and the WIN of a maximal nestedness matrix (Galeano et al. 
2008). The maximal nestedness matrix is a packed matrix that constrains the size and link number of to those of the original matrix and it is built by placing the links as close as possible to the rightmost cell in the matrix (Galeano et al., 2008).

Galeano J, Pastor JM, Iriondo, JM (2008) Weighted-Interaction Nestedness Estimator (WINE): a new estimator to calculate over frequency matrices. arXiv 0808.3397v1 [physics.bio-ph] 